This item was submitted to Loughborough's Research Repository by the author.

Items in Figshare are protected by copyright, with all rights reserved, unless otherwise indicated.

\title{
Epidemiology of injuries in Hong Kong elite badminton athletes
}

PLEASE CITE THE PUBLISHED VERSION

http://dx.doi.org/10.1080/15438620701405263

PUBLISHER

(c) Taylor \& Francis

\section{VERSION}

AM (Accepted Manuscript)

\section{PUBLISHER STATEMENT}

This work is made available according to the conditions of the Creative Commons Attribution-NonCommercialNoDerivatives 4.0 International (CC BY-NC-ND 4.0) licence. Full details of this licence are available at: https://creativecommons.org/licenses/by-nc-nd/4.0/

\section{LICENCE}

CC BY-NC-ND 4.0

\section{REPOSITORY RECORD}

Yung, Patrick Shu-Hang, Romy Hing-Kwan Chan, Fiona Chui-Yan Wong, Phoebe Wai-Ling Cheuk, and Daniel Tik-Pui Fong. 2019. "Epidemiology of Injuries in Hong Kong Elite Badminton Athletes". figshare.

https://hdl.handle.net/2134/21273. 
Dear Prof Hong, Editor of Research in Sports Medicine: An International Journal,

We would like to re-submit this paper titled "Epidemiology of injuries in Hong Kong elite badminton athletes” to the Research in Sports Medicine: An International Journal. This paper is not published nor submitted to other journals for consideration of publication. We have revised the manuscript in accordance with the reviewer's comments, with an accompanying letter stating the changes made and our answer to the reviewers.

Thanks for your attention. We look forward to hearing from you.

Patrick Yung, Romy Chan, Fiona Wong, Phoebe Cheuk, Daniel Fong 27 Dec 2006 


\begin{tabular}{|c|c|}
\hline Article title & Epidemiology of injuries in Hong Kong elite badminton athletes \\
\hline Author & $\begin{array}{l}\text { Patrick Shu-Hang YUNG }{ }^{1,2} \text {, Romy Hing-Kwan } \mathrm{CHAN}^{2} \text {, Fiona } \\
\text { C.Y. WONG }{ }^{1} \text {, Phoebe Wai-Ling } \text { CHEUK }^{2} \text {, Daniel Tik-Pui } \\
\text { FONG }^{1}\end{array}$ \\
\hline Affiliation & $\begin{array}{l}{ }^{1} \text { Department of Orthopaedics and Traumatology, Prince of } \\
\text { Wales Hospital, Faculty of Medicine, The Chinese University of } \\
\text { Hong Kong, Hong Kong, China. } \\
{ }^{2} \text { Sports Medicine Department, Hong Kong Sports Institute, Hong } \\
\text { Kong, China. }\end{array}$ \\
\hline $\begin{array}{l}\text { Corresponding } \\
\text { author }\end{array}$ & $\begin{array}{l}\text { Dr Patrick Shu-Hang YUNG, } \\
\text { Department of Orthopaedics and Traumatology, Prince of Wales } \\
\text { Hospital, Faculty of Medicine, The Chinese University of Hong } \\
\text { Kong, Hong Kong, China. } \\
\text { Phone: } 26461477 \\
\text { Fax: 26463020 } \\
\text { Email: patrick@ort.cuhk.edu.hk }\end{array}$ \\
\hline Acknowledgement & N/A \\
\hline Running head & Injuries in Hong Kong elite badminton athletes \\
\hline
\end{tabular}




\begin{abstract}
This study retrospectively reviewed the injury epidemiology on 44 Hong Kong elite badminton players in 2003. Team training records were reviewed to retrieve the training and competition hours, while the medical records from the physiotherapy department were reviewed to obtain the information of injuries. A total of 253 injuries (128 recurrent and 125 new injuries) were recorded, which accounted for an overall incidence rate of 5.04 per 1000 player-hours. Elite senior athletes had a higher incidence rate of recurrent injuries, while elite junior and potential athletes had higher incidence rate of new injuries. A total of 1219 visits (4.82 per athlete) to the physiotherapy department were recorded, which cost HK\$ 487,600 (HK\$ 1,928 per injury). Most new injuries were strain (80 injuries), and the most frequently injured body sites were the back (17 injuries), the shoulder (15 injuries), the thigh (15 injuries) and the knee (15 injuries). One-sided exact test showed that a previous injury experience significantly associated with the occurrence of new injury.
\end{abstract}

Keywords: Racquet sports, athletic injuries, sprains and strains

\title{
Introduction
}

Badminton injuries accounted for 1-5\% of all sports injuries (Fahlstrom et al. 1998b; Hoy et al. 1994; Kroner et al. 1990). In Hong Kong, a previous prospective survey on public participants showed that badminton accounted for $5.1 \%$ of total sports injuries attending a Sports Medicine clinic (Chan et al. 1993). It ranked sixth after soccer (13.9\%), basketball (13.4\%), volleyball (7.1\%), long-distance running (6.3\%) and cycling (6.3\%). Jorgensen and Winge (1987) reported that the incidence rate was 2.9 per 1,000 player-hours, which was much lower than those injury incidence rates for contact sports such as soccer (Junge and Dvorak 2004), rugby (Best et al. 2005) and 
basketball (McKay et al. 2001) that often exceeded 10.0 per 1,000 player-hours. However the prevalence differed for specific population. An epidemiology study in Ireland (Weir and Watson 1996) on 266 adolescents reported that badminton is the top sport with the most injuries. The incidence was 7.1 per 1,000 player-hours, which was higher than that of gymnastics (6.8), rugby (6.0) and basketball (5.6).

In general, males were more frequently injured than female badminton players (Jorgensen and Winge 1987, 1990), but, when the higher participation rate of male players was considered, the incidence rate did not differ much between genders (Weir and Watson 1996). Hensley and Paup (1979) reported that the incidence rate in terms of injuries per person per year for male and female competitive badminton players were 0.09 and 0.14 respectively. Jorgensen and Winge (1990) reported that injury rate was higher in training than in competition, which was in contrast to most other sports, i.e., Brooks et al. reported that the injury incidence in the professional English Rugby union was 91 per 1000 player-hours in match (Brooks et al. 2005a) and was 2.0 per 1000 player-hours in training (Brooks et al. 2005b). In using the Abbreviate Injury Scale (AIS) to quantify injury severity, Fahlstrom, Bjornstig and Lorentzon (1998b) reported that $51.3 \%$ of badminton injuries were minor and $48.7 \%$ were moderate, while Hoy et al. (1994), in their work, reported that 17\% were minor, 56\% were moderate and $27 \%$ were severe.

Most badminton injuries ( $74 \%$ ) are chronic overuse injuries (Jorgensen and Winge 1987), which mostly ( 90\%) involved the lower extremities (Kroner et al. 1990). However, upper extremity injuries also occurred, and they were rather unique to racquet sports (Lees 2003). Previous reported badminton injuries from epidemiology surveys and case studies included Achilles tendon rupture (Fahlstrom et al. 1998a), 
ankle ligamentous sprain (Fahlstrom et al. 1998b; Hoy et al. 1994), ankle fracture (Hoy et al. 1994), eye trauma (McWhae and LaRoche 1990), shoulder impingement (Lo et al. 1990), shoulder dislocation (Hazmy and Parwathi 2005), wrist injuries (Helal 1978), tennis elbow (Jorgensen and Winge 1990), muscle cramps, blisters and strains (Hensley and Paup 1979). Among all these injuries, epidemiology studies showed that the mostly injured sites were ankle (23.5\%), knee (14.0\%), foot (12.5\%), arm (8.5\%) and leg (5.4\%) (Fong et al, 2007).

Badminton is one of the thirteen current elite sports in Hong Kong receiving comprehensive support from the Hong Kong Sports Institute to enhance the opportunities to excel in international competitions. In public, it is also the second most popular recreational sport in Hong Kong, accounting for $6 \%$ of the total sport participation of the population (Hong Kong Sports Institute 2003b). Among university students, it accounts for about one-tenth of total participation (10.5\%) which ranks fourth after swimming (15.3\%), basketball (14.9\%) and cycling (13.2\%) (Chan et al. 1984). Some previous studies reported a higher injury risk of recreational than elite players (Chard and Lachmann 1987; Fahlstrom et al. 1998b; Jorgensen and Winge 1990), but some reported similar risk among these players (Jorgensen and Winge 1987). Epidemiology study on the recreational participants in Hong Kong was done (Chan et al. 1993). The aims of this study were to retrospectively review the medical record of the Hong Kong elite badminton players from January to December 2003, in order to describe the injury patterns and for evaluating future injury prevention directions for the elite badminton athletes. 


\section{Methods}

\section{Subjects}

All registered badminton athletes $(n=44)$ under the elite training scholarship scheme at the Hong Kong Sports Institute during the year 2003 were included in this study. Their demographics were shown in Table 1 . Their performance levels were categorized as elite senior athletes, elite junior athletes and potential athletes. Elite senior athletes are 21 or older in age and are already in the scholarship program for intensive training. Elite junior athletes are younger than 21 and have been recommended by head coach to join the elite senior team. Potential athletes are not scholarship athletes and are younger than 15 years old, and have been selected from different districts of the territory to receive focused and systematic training in badminton. Ethics approval for this study was granted by the Human Research Ethics Committee of Hong Kong Sports Institute.

\section{Data collection}

All data was collected in the form of retrospective review of the medical records for the period from January to December of 2003. Athlete player-hours for both training and competition were obtained from the team record database. Two sports physiotherapists with 14 and 10 years of experience, served as reviewers and took part in the review process according to a pre-determined format of data extraction. Each injury record was reviewed, and was identified if it was new or recurrent injury. New injury was defined as those occurring for the first time in the year (from 1 January 2003 to 31 December 2003), which had no record documenting its presence in the year prior to its occurrence. Recurrent injury was defined as all other injuries that were chronic in nature, previously treated in physiotherapy, and had occurred within a year from to its first occurrence according to the physiotherapy record. Information on 
whether the injury happened during training or competition was also recorded. Total number of visits for new and recurrent injury was also recorded.

Additional information was retrieved for new injury cases. Each new injury was identified as training or competition injury according to the time of its occurrence. Injury type of each new injury was also identified by operational definitions. A sprain was defined as a minor ligamentous injury which required no surgery and caused no major time off from training or competition. Ligamentous injury was defined as major ligamentous damage that required surgery and led to major time off (i.e. more than one month) from training or competition. A strain was defined as muscular fiber, or tendon tear, including acute or chronic tendinopathy. A fracture was defined as bony damages resulted in discontinuity of trobeculae with radiographic confirmation. A contusion was defined as local soft tissue injury caused by a direct collision without a break in the skin and with a subcutaneous hemorrhage. A facet injury was defined as the presence of back pain to one side of the spine associated with muscle spasm, which gets worse with backward or side trunk bending, or prolonged standing. A disc injury was defined as the presence of back pain, which gets severe with increasing intra-abdominal pressure when sneezing and coughing, or with forward trunk bending. In case of uncertainty, the two reviewers discussed and decided the final classification based on mutual consensus. Injured body site was also identified in each new injury case.

\section{Data Analysis}

Total athlete player-hours of each of the three categories of athletes were recorded. Incidences per 1000 player-hours and visit per injury for new and recurrent injury were calculated. Chi-square tests were performed to examine significance difference among recurrent and new injury among the three categories of athletes. New injury cases, incidences per 1000 player-hours for training and competition 
injury, injury types and injured body sites were also reported.

Chi-square tests or exact tests were conducted to examine if previous injury is associated with new injury incidence (1-sided test), and to examine if the proportions of sustaining injury are equal among gender and categories of athletes with difference performance level (2-sided test). Significance level was set at the 0.05 level.

\section{Results}

Exposure hours for training and competition for elite senior, elite junior and potential athlete groups were shown in Table 2. The overall exposure hours during the one-year study period was 50,195.47 hours. A total of 253 injuries (128 recurrent and 125 new injuries) were recorded during the study period (Figure 1). Chi-square showed a significance difference $(\mathrm{p}<0.05)$ among the total number of injury sustained by the athletes in different categories. Elite senior athletes sustained more recurrent injuries (98 cases, 62.0\%) while elite junior and potential athletes sustained more new injuries (elite junior: 37 cases, 61.7\%; potential: 28 cases, 80.0\%). Incidence rates of recurrent and new injuries were shown in Figure 2. The incidence of all injuries for all athletes was found to be 5.04 per 1000 player-hours in overall; it was highest for elite senior athletes (7.38), followed by elite junior (5.03) and potential athletes (2.07). Elite senior athletes had the highest incidence rate of recurrent injuries (4.58), while elite junior athletes had the highest incidence rate of new injuries (3.10).

The numbers of visits to physiotherapy treatment and visits per injury are shown in Figure 2. The total number of physiotherapy treatments provided was 1219, which cost HK\$487,600 in total. Chi-square showed a significance difference $(\mathrm{p}<.05)$ among the total number of visits due to new and recurrent injuries by the athletes in different groups: elite senior athletes had more visits due to recurrent injuries (460 cases, 56.9\%), while elite junior and potential athletes had more visits due to new 
injuries (elite junior: 182 cases, 70.8\%; potential: 127 cases, 83.0\%). Overall, the majority of the physiotherapy treatments were delivered to the elite senior group (809 cases, 66.4\%), while the visits per injury was also highest for this group (Recurrent: 4.69, New: 5.82, Overall: 5.12). The overall visit per injury among all athletes was 4.82 and the cost for each injury was $\mathrm{HK} \$ 1,928$.

The total number of new injuries was 125 (Figure 3). Exact test showed significant difference of the number of new injuries among groups $(\mathrm{p}<0.05)$. Elite senior athletes sustained more injuries in training (44 cases, 73.3\%) than in competition, so did elite junior (31 cases, 83.8\%) and potential athletes (28 cases, 100.0\%). In overall, about half of the injuries were sustained by the elite senior group (60 cases, 48.0\%). The overall injury incidence rate of new injury was 2.49 per 1000 player-hours. Both elite senior and elite junior athletes had higher incidence rates of injuries in competition than in training (elite senior: 3.78 vs 2.56; elite junior: 5.94 vs 2.84), but no competition injuries were recorded from the potential athletes.

Details of new injuries among injury types and injured body sites were shown in Table 3. Most of the injuries were strain (80 cases, $64.0 \%$, incidence rate $=1.59$ ), followed by sprain (18 cases, $14.4 \%$, incidence rate $=0.36$ ) and facet injuries (18 cases, $14.4 \%$, incidence rate $=0.36$ ). The incidence rate patterns among the three groups were similar, with these three injuries dominating. Contusion and disc-related problems were with lower incidence rate (incidence rate $=0.06$ ). There were no fracture and ligamentous injuries. Three other injuries were reported, including an acromioclavicular joint subluxation, a labral lesion of the hip, and a meniscus injury of the knee. Among body sites, lower extremity dominated (incidence rate $=1.24$ ), while the dorsal (incidence rate $=0.64$ ) and the upper extremity (incidence rate $=0.62$ ) accounted for similar incidence rates. Overall, the most often injured body sites included the back (0.34), the shoulder (0.30), the thigh (0.30) and the knee (0.30). For 
elite senior athletes, head and neck injuries, wrist injuries and ankle injuries also showed apparent dominance (incidence rate $=0.23$ ). Ankle injuries ranked second in potential athlete group (incidence rate $=0.30$ ). The overall incidence rate of lower extremity injuries for elite junior athletes was highest (1.76).

One-sided exact test showed that a previous injury experience significantly associated with the occurrence of new injury $(\mathrm{p}<0.05)$. Chi-squares test showed no significant association between new injury incidence with gender or categories of athletes with difference performance levels.

\section{Discussion}

The current study demonstrated that the incidence of injury for Hong Kong elite badminton players was found to be 5.04 per 1000 player-hours, which was comparable to the figure reported in Denmark (2.9 - Jorgensen and Winge 1987) and Ireland (7.1 - Weir and Watson 1996). The most frequent injuries were strains and sprains as reported in other studies (Hoy et al. 1994; Kroner et al. 1990). In a one-year study examining the epidemiology of badminton injuries based on case record collected at the casualty departments of two hospitals in Denmark, Kroner et al. (1990) reported a high percentage of sprains and ligament ruptures (58.5\%) while 19.8\% had muscle injuries (i.e. strains). Hoy et al. (1994) also reported 55\% of the injuries were sprains among all other injuries of the 100 badminton injuries registered in the casualty ward of a hospital in Denmark during a one year period. The classifications of injuries were different in these two studies and both presented injury rate as a percentage of all injuries registered during the study periods without specification of exposure. In addition, methodological differences and the use of different denominators in presenting injury rate hinder meaningful comparisons of the current study with the others. 
In regards to the incidence of strains across categories, the elite junior athletes had the highest incidence rate, followed by the elite senior, and then the potential athletes. We postulated that the elite junior athletes are going through transition from less intensive training to very intensive training resulting in high tensile loading and stresses on their musculoskeletal system. As some athletes started to adapt to the high intensive training load and volume, the incidence rate decreases among the elite senior group. Clinically, we have observed some athletes starting to develop chronic tendinopathy during this transition stage. Change in tendon load (Clement et al. 1984) and sudden repeated tensile overload of the musculoskeletal tendinous unit (Kujala et al. 1989) have been suggested to be associated with the aetiology of tendinopathy.

The incidence of facet problem was also high and ranked second place among all types of injuries in the current study. None of the past studies reported such type of injuries among badminton players. This could be a result of differences in adopting different classification systems between studies. The injury type information was extracted from the physiotherapy documentation in the current study. It appeared that facet problem was one of the most common diagnoses made by physiotherapists at the Sports Institute during the management of these badminton players. As the badminton sport often involves repetitive extension of the lumbar spine during overhead or jumping smash, the high incidence rate of facet problem and its frequent occurrence in the low back region may be a reflection of the loading pattern of specific body region (i.e. lumbar spine) in badminton players and may help direct further study in examining the injury mechanism of low back pain among this particular group of athletes. Facet joint failure as a result of repetitive lumbar extension has been suggested as a cause of low back pain (Yang and King 1984).

Another back-specific injury was disc problem. Only three incidences of disc problems in the senior athlete category were recorded. Two episodes were noted in the 
same player aged 28 and another in a 26-year-old player. All three episodes were confirmed by magnetic resonance imaging. This finding was supported by our current understanding that repetitive axial torsion of the lumbar spine, as happened during some of the badminton movements, may result in circumferential tears in the annulus fibrosus (Farfan et al. 1970) and this process may be worsened with degeneration and/ or aging. Being older and having participated for a longer period in the sport may have made them more susceptible to develop discogenic low back pain. There could also be other factors at play resulting in a relative low incidence rate of disc problem in this group of players. Such factors may have to be further researched in future studies.

On examining the incidence of injury by body regions, injuries in the back, shoulder, thigh and knee were the most common across all three categories. The high incidence rates of injuries in these body regions provide good evidence for specific evaluation of these targeted areas in pre-participation examination, musculoskeletal screening examination and possibly conditioning programs in the future. Athletes from different categories demonstrated slightly different injury patterns by body regions. Both back and shoulder injuries had the highest incidence rates in the elite senior category; knee injury was the most common in the elite junior category followed by shoulder, thigh and back. In the potential category, the distribution of injury sites was more even except that of the back and the ankle, which appeared to have a relative higher incidence rates compared to the other injury sites. Overall, knee injury and shoulder injury in the elite junior athletes were the highest and second highest among all injured body regions across all three categories. These results demonstrate the need to call for slightly different body region-specific conditioning programs for athletes of different category. Common to all categories is probably back-specific conditioning program. 
Injury prevention research has been described by van Mechelen et al. (1992) as a four step sequence. Investigating the epidemiology of the problem is the first step of the process, which should logically lead to the second and the most critical step in establishing the causes or mechanisms of specific injuries. Based on our current findings regarding the specific types and locations of injuries, it would appear that structured screening examination should be specifically planned to evaluate the back, shoulder and knee regions for these athletes. The latter two regions are particularly important and should be emphasized when evaluating the junior elite athletes. Further studies should also aim at exploring the mechanisms of back, shoulder and knee injuries in the badminton athletes so as to develop specific conditioning programs for injury prevention.

Preventing both the first injury and re-injury represent a seemingly normal, but complex, target. The common denominator between the two is the need for the identification of the factors leading to injury and the development of the most appropriate preventive measure. Orchard (2001) distinguished between extrinsic factors principally inherent to sport activity (environment-related) and intrinsic factors related to individual features and profile (player-related). It was however not the purpose of this study to examine the possible extrinsic factors associated with incidence of new injury. It has also been suggested that intrinsic factors are more predictive of injury than the extrinsic factors (Orchard 2001). We studied primarily the associations between several intrinsic risk factors and the incidence of new injuries in the current study. Only the history of a previous injury was significantly associated with the incidence of new injury among all other intrinsic factors. It therefore appeared that the culprit for sustaining a new injury may be due to inadequate or inappropriate rehabilitation from an old injury. Clinically, some of the risk factors associated with the possible recurrence of the injury are, in all probability, 
already implicated in the initial injury. The persistence of mistakes or abnormalities in action represents an irrefutable component contributing to the re-injury cycle. Additional factors leading to chronicity may also come from the first injury itself through modifications in the muscle tissue and possible adaptive changes in biomechanics and motor patterns of sporting movements. The current study also suggested the association between previous injury and new incidence of injury was specific to the regions of the groin, hip and leg. As all these regions are part of the lower quarter, specific musculoskeletal examination of the lower quarter kinetic chain and biomechanical factors, such as muscle imbalance, compromised flexibility, strength deficits and anatomic abnormalities (malalignment - Lysens et al. 1991; Taimela et al. 1990) may help clarify the possible causes of such phenomenon.

Although playing level (Chard and Lachmann 1987; Fahlstrom et al. 1998b; Jorgensen and Winge 1987, 1990) and female gender (Jorgensen and Winge 1987, 1990) have been found to have a higher injury potential in some situations, they were not associated with incidence of new injury in the current study. With regard to the level of performance, we believe that at different performance levels, the athletes should have different skill levels and sporting experience, which may in turn modify their patterns of injury, including sustaining a new injury. The results of this study however do not support this notion. The small sample size in this study may not be able to truly reveal the role these specific factors play in the causation of incidence of new injury.

We also observed that elite senior athletes were more prone to sustaining recurrent injuries, while elite junior and potential athletes have relatively more new injuries. This probably demonstrates the difference in injury pattern between categories of athletes and possibly justifies the incorporation of specific prevention strategy such as conditioning programs for all categories. As the athletes participate 
longer in the sport, some of the injuries may have become chronic and tend to recur from time to time.

Another important finding of this study is that the injury incidences were significantly greater during competition than that during training. Competition definitely imposed additional physical and psychological stresses on the athletes and may lead to the higher incidence of injury. However, the two occasions should not be considered separately due to the intensive competition schedule for these athletes, especially in the elite senior category. Injuries during training, if not promptly and properly managed, may result in insufficient recovery and result in increased chance of new injury or re-injury.

There were more visits to physiotherapy treatment for recurrent injuries for elite senior athletes, and for new injuries for both elite junior and potential athletes. It therefore appeared logical to develop sound prevention strategy to reduce the number of recurrent injuries in the elite senior athletes and new injuries in the junior elite and potential athletes from the economical standpoint. Badminton players constituted about $8 \%$ of all the athletes in Hong Kong Sports Institute during the study period. However, they consumed about 35\% of the total sports medicine resources (including physical therapy, massage and medical services) during the same period (Hong Kong Sports Institute 2003a). The successful prevention of badminton injuries would definitely reduce the utilization of rehabilitation services at the department and may help reallocation of resources for other sports teams and for development of other services (e.g. structured prevention program) at the Institute.

Being a retrospective study in nature, the current study has missed out some pertinent information regarding the severity of injury, which can be expressed as the amount of time loss from training and competition. This can be an important determinant regarding the extent of injury. Additionally, mechanisms of injury can be 
explored from interviewing the injured athletes (Krosshaug et al. 2005), which may help in formulating specific strategy in the injury prevention process. All the above would justify to introduce a more comprehensive injury surveillance system. The key to meaningful epidemiology study lies in an organized data collection process and systematic analysis (Caine et al. 1996). The success of such process requires a coordinated effort from the sports medicine professionals, the coaches and the athletes. 


\section{References:}

Best JP, McIntosh AS, Savage TN (2005) Rugby World Cup 2003 injury surveillance project. British Journal of Sports Medicine, 39(11), 812-817.

Brooks JH, Fuller CW, Kemp SP, Reddin DB (2005a) Epidemiology of injuries in English professional rugby union: part 1 match injuries. British Journal of Sports Medicine, 39(10), 757-766.

Brooks JH, Fuller CW, Kemp SP, Reddin DB (2005b) Epidemiology of injuries in English professional rugby union: part 2 training injuries. British Journal of Sports Medicine, 39(10), 767-775.

Caine D, Caine C, Lindner K (1996) Epidemiology of Sports Injuries: Champaign IL: Human Kinetics.

Chan KM, Fu F, Leung L (1984) Sports injuries survey on university students in Hong Kong. British Journal of Sports Medicine 18(3): 195-202.

Chan KM, Yuan Y, Li CK, Chien P, Tsang G (1993) Sports causing most injuries in Hong Kong. British Journal of Sports Medicine 27(4): 263-267.

Chard MD, Lachmann SM (1987) Racquet sports--patterns of injury presenting to a sports injury clinic. British Journal of Sports Medicine 21(4): 150-153.

Clement DB, Taunton JE, Smart GW (1984) Achilles tendinitis and peritendinitis: etiology and treatment. The American Journal of Sports Medicine 12(3): 179-184.

Fahlstrom M, Bjornstig U, Lorentzon R (1998a) Acute Achilles tendon rupture in badminton players. The American Journal of Sports Medicine 26(3): 467-470.

Fahlstrom M, Bjornstig U, Lorentzon R (1998b) Acute badminton injuries. Scandinavian Journal of Medicine and Science in Sports 8(3): 145-148.

Farfan HF, Cossette JW, Robertson GH, Wells RV, Kraus H (1970) The effects of torsion on the lumbar intervertebral joints: the role of torsion in the production of disc degeneration. Journal of Bone and Joint Surgery - American Volume 52A(3): 468-497.

Fong DTP, Hong Y, Chan LK, Yung PSH, Chan KM (2007) A systematic review on ankle injury and ankle sprain in sports. Sports Medicine (in press).

Hazmy CH, Parwathi A (2005) Sports-related shoulder dislocations: a state-hospital experience. Medical Journal of Malaysia 60 Suppl C :22-25.

Helal B (1978) Chronic overuse injuries of the piso-triquetral joint in racquet game players. British Journal of Sports Medicine 12(4): 195-198.

Hensley LD, Paup DC (1979) A survey of badminton injuries. British Journal of Sports Medicine 13(4): 156-160.

Hong Kong Sports Institute, Research Department (2003a) Sports Medicine Service Utilization Review. Hong Kong: Hong Kong Sports Development Board. 
Hong Kong Sports Institute, Research Department (2003b) Sports Participation Survey 2001. Hong Kong: Hong Kong Sports Development Board.

Hoy K, Lindblad BE, Terkelsen CJ, Helleland HE, Terkelsen CJ (1994) Badminton injuries - a prospective epidemiological and socioeconomic study. British Journal of Sports Medicine 28(4): 276-279.

Jorgensen U, Winge S (1987) Epidemiology of badminton injuries. International Journal of Sports Medicine 8(6): 379-382.

Jorgensen U, Winge S (1990) Injuries in badminton. Sports Medicine 10(1): 59-64.

Junge A, Dvorak J (2004) Soccer injuries: a review on incidence and prevention. Sports Medicine, 34(13), 929-938.

Kroner K, Schmidt SA, Nielsen AB, Yde J, Jakobsen BW, Moller-Madsen B, Jensen J (1990) Badminton injuries. British Journal of Sports Medicine 24(2): 169-172.

Krosshaug T, Andersen TE, Olsen OE, Myklebust G, Bahr R (2005) Research approaches to describe the mechanisms of injuries in sport: limitations and possibilities. British Journal of Sports Medicine 39(6): 330-339.

Kujala UM, Aalto T, Osterman K, Dahlstrom S (1989) The effect of volleyball playing on the knee extensor mechanism. The American Journal of Sports Medicine 17(6): 766-769.

Lees A (2003) Science and the major racket sports: a review. Journal of Sports Sciences 21(9): 707-732.

Lo YP, Hsu YC, Chan KM (1990) Epidemiology of shoulder impingement in upper arm sports events. British Journal of Sports Medicine 24(3): 173-177.

Lysens RJ, de Weerdt W, Nieuwboer A (1991) Factors associated with injury proneness. Sports Medicine 12(5): 281-289.

McKay GD, Goldie PA, Payne WR, Oakes BW, Watson LF (2001) A prospective study of injuries in basketball: a total profile and comparison by gender and standard of competition. Journal of Science and Medicine in Sport, 4(2), 196-211.

McWhae J, LaRoche GR (1990) Badminton-related eye injuries. Canadian Journal of Ophthalmology 25(3): 170.

Orchard JW (2001) Intrinsic and extrinsic risk factors for muscle strains in Australian football. The American Journal of Sports Medicine 29(3): 300-303.

Taimela S, Kujala UM, Osterman K (1990) Intrinsic risk factors and athletic injuries. Sports Medicine 9(4): 205-215.

van Mechelen W, Hlobil H, Kemper HC (1992) Incidence, severity, aetiology and prevention of sports injuries. A review of concepts. Sports Medicine 14(2): 82-99.

Weir MA, Watson AW (1996) A twelve month study of sports injuries in one Irish 
school. Irish Journal of Medical Science 165(3): 165-169.

Yang KH, King AI (1984) Mechanism of facet load transmission as a hypothesis for low-back pain. Spine 9(6): 557-565. 